\title{
IgG IgM IgA Total Measurement
}

National Cancer Institute

\section{Source}

National Cancer Institute. Ig G IgM IgA Total Measurement. NCI Thesaurus. Code C111233.

The determination of the total amount of $\lg G, \lg M$, and $\lg A$ present in a sample. 